\title{
Rethinking public participation in infrastructure projects
}

1 S. Thomas $\mathrm{Ng} M S C$, PhD, FRICS, MCIOB, MAPM, FHKIS, FHKICM, MHKIPM, RPS(QS)

Associate Professor, Department of Civil Engineering, The University of Hong Kong, Pokfulam Road, Hong Kong
2 Terry H. Y. Li MSC

PhD candidate, Department of Civil Engineering, The University of Hong Kong, Pokfulam Road, Hong Kong

3 James $\mathbf{M}$. W. Wong BSC, PhD

Postdoctoral Fellow, Department of Civil Engineering, The University of Hong Kong, Pokfulam Road, Hong Kong
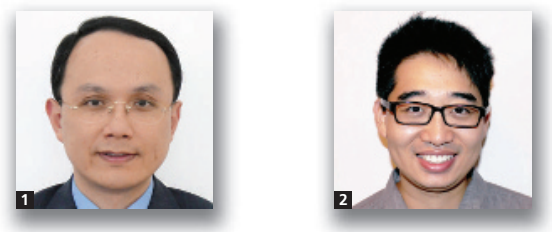

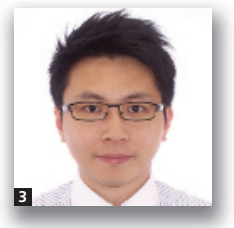

The mission of any public infrastructure and construction (PIC) projects is to improve the well-being of the society. In spite of this, as some of these projects might impact on the environment and affect the habitat of local residents, it is not unusual to attract criticism or even opposition from various stakeholder groups. Consequently, there is an increasing concern about the effectiveness of public participation for PIC projects. The authors strive to examine the salient elements of public participation by considering the questions of 'who', 'what' and 'how' in the process. The paper begins by reviewing the international public participation practices and the models proposed by various researchers. The key aspects to be considered during the public participation process are then highlighted. The paper concludes by proposing a comprehensive participatory framework for PIC projects, especially those of a highly sensitive nature. The results show that the standpoints of various stakeholders can be rather diverse and it is necessary to ensure a consensus is reached at different project stages through a well-planned, whole-cycle participatory exercise in order to maximise the chance of project success. More importantly, better acceptance towards other views and more education on the importance of public participation are needed to ensure that society benefits from economic and social development without sacrificing the rights and best interests of the minority groups.

\section{Introduction}

Maintaining a harmonious society is the governing philosophy behind many governments. To achieve this, policy makers strive to convey their plans to the general public and solicit opinions from a cross-section of the community before any key policy decisions are reached (Rowe and Frewer, 2000, 2004). This is particularly the case for public infrastructure and construction (PIC) projects as the provision of this type of facilities can be controversial and may affect the interests of many people in the society (Deegan and Parkin, 2011; Song et al., 2011). Therefore, a thorough understanding of the needs of the society at large, the grievances of the affected citizens, and the suggestions of the concerned groups is desirable. This should help to ensure the required PIC facilities are properly planned, designed, built, operated and demolished to serve the well-being of various parties in a complex society (Woltjer,
2009). By relieving the tension between the government and society, essential facilities or services can be delivered smoothly and satisfactorily (Batheram et al., 2005; Song et al., 2011).

Instead of merely placating the community without actually involving them in the decision process, Arnstein (1969) urged policy makers to consider carrying out public participation to evoke citizens' power through partnership, power delegation and citizen control. Public participation requires the involvement of individuals and groups that are positively or negatively affected by a proposed intervention (e.g., a project, a program, a plan, a policy)' (André et al., 2006, p. 1). Through public participation, the chance of project success should increase as the needs of various sectors of the society would have been thoroughly considered before a finalised plan and solution is derived (Giddings et al., 2010; Landge et al., 2005; Woltjer, 2009). 
Rethinking public participation

in infrastructure projects

$\mathrm{Ng}$, Li and Wong
Despite the desired benefits of getting the general public involved in PIC schemes, in many cases the process is far from satisfactory, as reported in the literature, for example in Moore and Warren (2006). In some developing countries where public participation is yet to mature, authorities are cynical about the value of involving the public in making decisions, as they worry that an over-active citizenry could lead to social disorder and conflict (Shan and Yai, 2011; Song et al., 2011), and this could increase the chance of project failure (Moore and Warren, 2006). Besides, as public participation can be administratively costly and may result in protracted delay, policy makers would try to avoid or fast track the participatory process, and this policy can also be seen in some advanced and democratic states (Creighton, 2005; Wang, 2007). Compared with the health care and education sectors, the development of public participation in the construction industry is still very rudimentary (Rowe and Frewer, 2004), and there is a need to make the participatory process more systematic (Creighton, 2005; Song et al., 2011).

This study, therefore, is intended to stimulate thought and discussions on the key aspects to be considered when planning and conducting public participation for PIC schemes. The paper begins by examining the international practices on how to conduct a public participation exercise effectively and efficiently. The participation models and methods as proposed by researchers are reviewed and compared. Based on the results of literature review, the factors governing the participatory process are highlighted. By capturing the lessons from the Guangzhou-Shenzhen-Hong Kong express rail link project, a comprehensive participatory framework for PIC projects, especially those of a highly sensitive nature, is proposed.

\section{International practice}

In recent times, there has been an international trend toward increased involvement of the public in the decision-making process as the virtues of public participation have been more and more recognised by governments, practitioners, regulators and academics all over the world (Rowe and Frewer, 2005). Several influential organisations, such as the World Bank, the European Union, the Organization for Economic Co-operation and Development and the United Nations have attached great importance to public participation as a way to enhance the quality of governance and public administration (CCSG, 2007).

Meanwhile, relevant documents have been published by the governments of some developed countries like the UK, the USA and Canada, which are undoubtedly the frontiers in public participation. For instance, the government's Audit Commission in the UK has released a document entitled Connecting with Users and Citizens (Audit Commission, 2002), which lays down the underlying principles for effective public participation such as commitment and culture, support and structure, diversity and representation, handing over control, learning from experience, and real results. In the USA, the Public Participation Planning Guide produced by the Department of Energy (DOE, 1999) stresses the importance of clearly defining the expectations, involving the interested stakeholders in every step of a decision and allowing the participants to influence the decision. In contrast, the Guidelines for Public Participation published by the Department of Justice (DOJ, 2009) in Canada puts mutual trust and respect between the decision makers and participants throughout the participation process as the core of public participation.

However, for developing countries like China, the development of public participation is still very rudimentary. Unlike the western participatory practice which emphasises the solicitation and analysis of public opinions throughout the project cycle (i.e. the planning, design, construction, operation and demolition of PIC facilities), public participation in China is only applied to those schemes entailing an environmental impact assessment (EIA) (Zhang and Jennings, 2009). Besides, Chinese participatory practice usually takes the form of informing the public of the finalised plan or design rather than inviting them to express their opinions before a decision is made (Shan and Yai, 2011). Such a 'tokenism' participatory approach would only impose a burden on people to cooperate and support the government to implement the project. This would definitely go against the true spirit of public participation of emphasising the rights of people at large (Arnstein, 1969; Creighton, 2005).

\section{Public participation models}

In the absence of a comprehensive guideline on public participation and in order to improve the rigour of public participation, researchers have put forward various models relevant to this type of decisions, and examples of these include Hampton's (1977) public participation schema and Creighton's (2005) public participation framework.

Hampton (1977) proposed a public participation schema according to three stages: dispersing information; gathering information; and interaction between planning authority and public. Under Hampton's schema, the techniques for information dispersal, information gathering and interaction should be translated into two sets of questions to explain the varied amounts of information to be released or gathered and the different scopes of public being informed or consulted, and this could then be used to determine the different levels of public participation. The schema as presented by Hampton (1977) is based on the assumption that the more information is dispersed by the planning authorities, the more data will be gathered from the participants and hence a more effective interaction will be achieved between decision makers and the public. 
Creighton (2005), however, believed that public participation should become an integral part of the decision-making process, as there is no 'one-size-fits-all' plan for public participation. Instead, a plan for public participation can be produced by thinking through the issues in a systematic manner in order to meet the unique requirements of each project (Creighton, 2005). To help practitioners in planning or organising a public participation activity that will fit their unique circumstances, Creighton (2005) considered it necessary to divide the planning into three stages

(a) decision analysis

(b) process planning

(c) implementation planning.

Through decision analysis, practitioners should be able to identify the appropriate participants, the decision makers, the problems being solved, the stages of the decision-making process, the constraints and the required participation level. At the process planning stage, attention should be shifted to what specific targets the practitioners would like to achieve by going through each step of the public participation exercise, and this would help determine the most appropriate techniques to enhance the participation. Practitioners are then required to devise an implementation plan according to the identified participatory techniques so as to ensure public opinions are effectively and efficiently collected.

Since there is a rather long time gap between the two models mentioned above, it is not only worth revisiting their pros and cons but also timely to review the latest development of the participatory theory. Sewell and Phillips (1979) believed that the attractiveness of Hampton's model lies with the advocacy of a dynamic public participation process and the emphasis on a differential treatment to various segments of community to best satisfy their goals. Despite this feature, Hampton's model ignores the importance of project efficiency and the cost involved in a participation programme, and these features are contrary to today's stringent project requirements and social interest in some cases. In contrast, Creighton's model aims at reaching a consensus within the project's time and cost constraints so as to maximise the benefits to the community. Creighton's model is, therefore, more applicable to the contemporary scenario and should form the basis when developing a participatory framework for PIC projects.

\section{Issues to be considered in public participation}

Despite the global trend towards greater public participation in the decision-making process, the process is still regarded by some governments, especially those in developing countries, as a non-value-adding task when it comes to PIC projects. This could be partly attributed to the concern that public participation can be time consuming and expensive. A lack of systematic framework to guide the participatory process for different types and scales of PIC facilities may also contribute to the failure of some public participation exercises. In some cases, the planning of participatory activities is left to the public relations companies, which may not even have a good grasp of the project's nature and sensitivity. In contrast, the project team members may not have good enough communication skills to solicit opinions from the general public. CEDD (2009) suggested forming a consultation team comprising representatives from the government, consultants and other project team members at an early stage of a PIC project. The team will then organise the whole participatory exercise by first classifying the proposed project according to the sensitivity level. While projects of low and medium sensitivity may largely attract local residents' attention, highly sensitive projects are usually of strategic significance and national/regional interest. Therefore, a more comprehensive participatory strategy should be developed for highly sensitive projects to ensure appropriate time and resources are allocated to the participatory exercise, commensurate with the potential impact on the community (CEDD, 2009; Deegan and Parkin, 2011). Failing to do so may result in strong opposition from the public, as in the case of the Guangzhou-Shenzhen-Hong Kong express rail link project (Hayllar, 2010; Zhu, 2009a, 2009b). To avoid this requires a thorough consideration of the issues of 'who', 'what' and 'how' throughout the participatory process (Figure 1).

\subsection{Participants as opposed to decision-makers}

It is recognised that public participation is a people-oriented process and people are the centre of every public participation programme (Giddings et al., 2010; Neverauskas and Tijūnaitienè, 2007).

\subsubsection{Who should participate?}

According to Creighton (2005), public participation in principle involves every person, although it may not be possible to reach all the individuals and some may not be interested in becoming involved. However, it is necessary to ensure that the participants that are involved represent those who can influence the project process and/or final results, whose living environment is positively or negatively affected by the project, and who receive direct and indirect benefits and/or losses from it (Deegan and Parkin, 2011; El-Gohary et al., 2006; Song et al., 2011). These include

(a) government/project initiators

(b) lay public who are affected by, or have interest in, the proposed project

(c) private organisations, such as the design institutes and construction companies

(d) professional organisations and educational institutions 


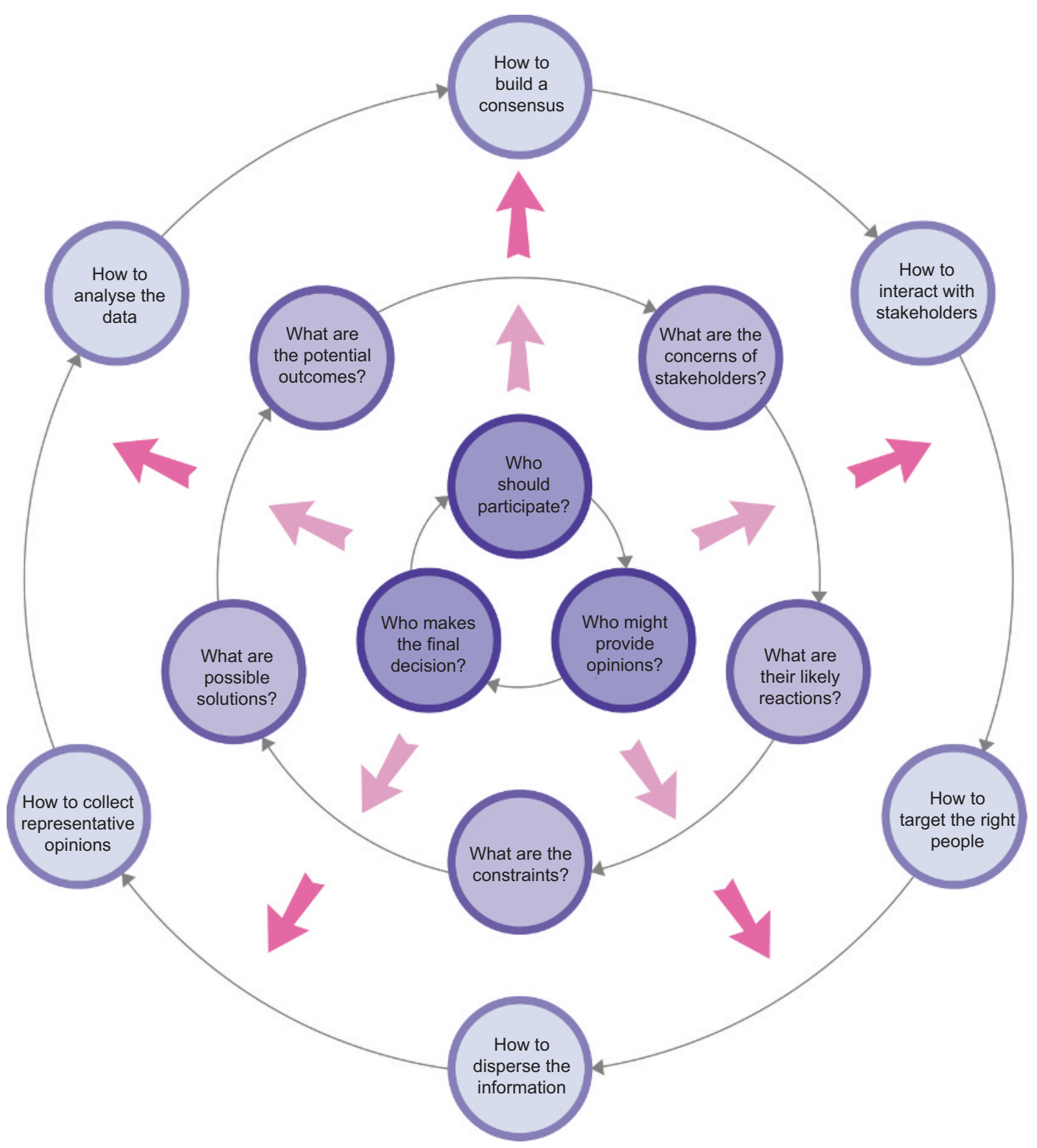

Figure 1. A systemic process for public participation

(e) pressure groups such as the non-government organisations (NGOs) and mass media.

\subsubsection{Who might provide opinions?}

While it is reasonable to expect that people would try to influence the planning and design of a project to bring it in line with their individual concerns and needs (Olander and Landin, 2008), in reality not every participant, particularly in the eastern societies like China, is keen to voice his or her concerns during the participation process (Plummer and Taylor, 2004), and this may lead to biases when the participatory activities are dominated by the activists. There might be a situation where the silent majority are in favour of the proposal, and decision makers should not misconceive this as a lack of public support and halt the project. In addition to the traditional eastern culture of compliance, the education level of the participants may also affect their willingness to express views either positively or negatively (Lee and Chan, 2008). People with weak proficiency in literacy, such as those in depressed areas, may be penalised should inappropriate participation techniques like public hearings or legal notices be used, as they may not be able to understand fully the details of the project or bring forward their concerns accordingly (Plummer and Taylor, 2004). 
Rethinking public participation

in infrastructure projects

$\mathrm{Ng}$, Li and Wong
The maturity of participatory process in some western countries may be attributed to a more liberal culture and the better educational level of citizens (Lee and Chan, 2008). In order to cope with the rapid expansion of PIC projects and the increasing expectations of social equality, the government of some developing countries like China are moving towards a more transparent, democratic and comprehensive participatory decision-making process (Li et al., 2012; Song et al., 2011). By incorporating the constructive comments of NGOs and academia on the technical aspects of a project, the participatory process would take into account the views of the silent majority as well (Common Ground, 2005; Giddings et al., 2010).

\subsubsection{Who makes the final decision?}

Traditionally, the government has the ultimate authority in determining what PIC facilities should be provided, irrespectively of the existence of any public participation process. Despite that, Common Ground (2005) recommends government departments, officials and decision makers to

(a) commit to the participation process

(b) respect the results of the public participation process

(c) proactively communicate with all the stakeholders in the participation process

(d) treat all the stakeholders fairly regardless of their different social-economic backgrounds

(e) be transparent and reliable during the participation process.

Even so, in a democratic society the government should consider involving a cross-section of the society in the decisionmaking process in order to improve the credibility and acceptability of the decision reached. A balanced composition of decision makers would also help prevent the decision being hijacked by certain political groups (Deegan and Parkin, 2011).

\subsection{Setting the objectives}

The public is unlikely to participate or take the participation process seriously if they feel that a project decision has already been made. This is a problem in both developing and developed countries and can adversely affect the effectiveness and efficiency of the participation programme or even the whole project (Creighton, 1999). It is, therefore, important for the decision makers to reassure the public that their concerns will be seriously considered before a final decision is reached (Deegan and Parkin, 2011; IAPP, 2007; Song et al., 2011). Once the participants realise their value in the decision-making process, the organiser(s) can start identifying stakeholders' concerns and project constraints. Through these findings, clear objectives can be established to drive the public participation process.

\subsubsection{What are the concerns of stakeholders?}

With a diverse social, political and educational background, the interests or concerns of every stakeholder involving in a public participation programme could vary (Olander and Landin, 2005). Some common concerns include the scheme's economic values (e.g. financial benefits or losses of the project); mandate (e.g. environmental impacts); proximity (e.g. air pollution and nuisance affecting the residences); philosophy (e.g. influences to people's culture, habit and religion); usage (e.g. any threats to valuable resource or resource availability) (Creighton, 1999).

\subsubsection{What are the constraints?}

Not all the concerns of stakeholders can be satisfied, as every PIC project would have its own constraints (El-Gohary et al., 2006). It is, therefore, important to find out what are the constraints of the project and establish the time and cost implications of any possible alternatives in overcoming the constraints. An example in Hong Kong is the GuangzhouShenzhen-Hong Kong express rail link project, which involves the acquisition of some farm land along the rail alignment. In this project, some affected residents demanded the preservation of their existing living mode by requesting the government to rebuild and reassemble their community elsewhere. Others proposed to relocate the terminal of the express rail link project from the city of Hong Kong to the border of China. Obviously, there are different constraints and considerations involved, including the technical feasibility and economic value of those options, and the government may not always find the alternatives acceptable, especially under a tight budgetary and time regime (Wang, 2007).

Policy makers should not lose sight of the institutional constraints and cultural constraints that apply to decision makers (Creighton, 1999; IFC, 1998; Song et al., 2011). Cultural constraints may be easier to handle as they are more regionally oriented, which can be resolved through better education. However, institutional constraints are more difficult to deal with as some of those constraints may not even have a solution. Creighton (1999) highlighted several examples of institutional constraints which include

(a) having already committed to a particular decision

(b) receiving internal opposition to conducting public participation on the issue

(c) being restricted to release the information.

Under those circumstances, the organiser(s) of the participatory exercise should consider the impacts induced by those constraints and introduce appropriate actions to ensure the public participation programme is valuable instead of merely meeting the planning procedures. 
Rethinking public participation

in infrastructure projects

$\mathrm{Ng}$, Li and Wong

\subsection{Achieving the goals}

Having established the objectives of the public participation programme, it is possible to decide how to achieve the goals. This involves a sensible selection and application of the participatory techniques. According to El-Gohary et al., (2006), the selection of participatory techniques depends on the principal direction of information flow involved in public participation programmes, namely

(a) information dispersing techniques (e.g. leaflet, publication, exhibition or media release)

(b) information gathering techniques (e.g. survey or questionnaire)

(c) interaction techniques (e.g. community meetings and workshops).

There is not one single best technique which would suit various types of stakeholders and the natures of different projects, and usually a combination of techniques is required for public participation (IFC, 1998).

\subsubsection{How to target the right people}

Instead of consulting a large number of people having a 'stake' in the proposed project, IFC (1998) suggested involving stakeholder representatives only in the decision-making process to achieve more efficient information dissemination and feedback collection, especially when the budget or the schedule is tight. Stakeholder representatives can be the leaders of various interest and affected groups, experts from professional institutions, academia, district councillors, politicians, citizens randomly selected from society, etc. To improve the representativeness, there should be a balanced composition of stakeholders (Deegan and Parkin, 2011; Song et al., 2011). However, as evident in Hong Kong, it is always a challenge to encourage the silent majority to take part in any participatory activities, and this could directly affect the decision on whether to go ahead with the development or not, especially when the silent majority is in support of the proposed scheme. Therefore, careful planning of the participatory groups, including the minority and general citizens, is absolutely indispensible (CCSG, 2007). To achieve this, the organiser(s) may consider involving the public to decide who are the right participants (CEDD, 2009).

\subsubsection{How to interact with stakeholders}

Two types of interaction occur when conducting public participation exercises: interaction between the policy makers and the involved stakeholders and interaction within the stakeholder groups. Common Ground (2005) suggested that an effective and efficient interaction can be achieved only if the policy makers can communicate with the involved stakeholders in an inclusive, accessible, transparent and fair manner. Otherwise, it would only give rise to an adversarial and confrontational environment without resulting in any improvement to the plan.
To facilitate interactions among the stakeholders, the social web, public forums, focus meetings and community workshops can be employed to help build a platform for all interested individuals and stakeholders to discuss the issues and debate on pros and cons of different alternatives and measures openly before putting them forward to the policy makers for consideration (Deegan and Parkin, 2011; Rowe and Frewer, 2000).

\subsubsection{How to disperse the information}

An exchange of information between the involved public and policy makers exists in every public participation programme. While the quality of such information determines the effectiveness of a public participation programme, the related public groups must be well informed to maximise the benefits of participation (Moore and Warren, 2006). According to DETR (2000) and El-Gohary et al. (2006), two types of information should be provided to the participants, and these are the information about the participation process along with the information about the proposed project. To improve the effectiveness of public participation, every citizen in the society should be informed of what, when and where various activities will be organised and how they can become involved (e.g. the process). In addition, people should fully understand the details of the proposed scheme and what constraints and limitations the government and project are facing (e.g. the project). The selection of information-dispersing techniques depends largely on the types of audience and it is necessary to emphasise the quality of information being released to the public to ensure it is complete, understandable and accessible (DETR, 2000).

However, the anticipated results can hardly be achieved if the information is released at an inappropriate time (i.e. after the key decisions are made), even with the use of suitable information-dispersing techniques (IAPP, 2007). Without the belief that their comments will be considered or incorporated in the final decision, participants may feel they are being cheated and will not take the participatory exercises seriously in future (Creighton, 1999).

\subsubsection{How to collect representative opinions}

There is no one single group or organisation that could represent the opinion of the whole society, and the representativeness and diversity of the opinions collected could affect the effectiveness of the public participation programme to a large extent. In order to ensure that stakeholders can participate according to their own level of interest, a number of different techniques to collect information from the involved public should be applied during the participation process, and these include focus groups, mail-in response forms, plebiscite, polls, surveys, questionnaires and so on (Creighton, 1999). The selection of appropriate informationgathering techniques is governed by the social and cultural 
Rethinking public participation

in infrastructure projects

$\mathrm{Ng}$, Li and Wong background of the involved public. For instance, questionnaires or polls might be suitable for gathering general opinions from society when a large number of people are being targeted. However, for more specific comments and suggestions, techniques like open forums and focus groups may be more appropriate (CEDD, 2009). Regarding the cultural factor, participants affected by the eastern traditional conservative culture are in favour of raising comments on an anonymous basis and this necessitates the use of such information-gathering techniques as mail-in response forms, questionnaire surveys, telephone interviews, and so on (Rietbergen-McCracken and Narayan-Parker,1998).

\subsubsection{How to analyse the data}

It is a good practice to analyse the data in a transparent way so that the participants can see how their comments are taken into consideration (Batheram et al., 2005). Otherwise, the public will lose faith in both the policy makers who proposed the public participation programme at the beginning and the design team members who convert the plan into detailed specifications and requirements. DETR (2000) argued that the involved public should pay more attention to the manner in which their comments are handled rather than the final outcome of the decision. In view of the importance of information analysis, the Cabinet Office (2010) put forward a six-step process to analyse comments solicited from participants so as to balance the interests of different stakeholder groups. Similarity, the representativeness and the level of support are the important issues to be addressed when balancing the comments raised by different groups of participants. Meanwhile, special attention should be paid when dealing with the comments collected from members of eastern societies, as the majority of them would choose to keep silent even if they support the proposed project.

\section{Consensus building}

Conducting public participation does not automatically guarantee a mutually agreeable solution, especially as the interests of various stakeholders vary. Should there be a gap between the policy makers and the society, it is necessary to try to minimise the differences in order to reach a consensus. The agreed solution may not necessarily be the same as what was originally proposed, as the bottom line is to work out a final decision that could reflect the interests of the wider community to maximise the benefits (DETR, 2000; Giddings et al., 2010).

Figure 2 illustrates the essence of public participation as a process of consensus building with due reference to the diverse interests or concerns of stakeholders. Four major groups of stakeholders have been identified as having an interest in a PIC project and they are the government and project initiator, affected groups, general public and users, as well as pressure groups and regulators. As the primary decision maker, the majority of government representatives would like to get the project approved for various reasons, not least the political agenda and budgetary considerations (Common Ground, 2005). Nonetheless, owing to internal differences, a government may not easily arrive at an internal conclusion about promoting a particular scheme (Creighton, 1999). On the other hand, the people affected by the project may be concerned about the compensation, disturbance, inconvenience and losses caused by the construction of the project. From the perspective of the general public and users, the overall social and economic values or impacts brought by the proposed scheme are their prime consideration (Creighton, 1999). One should not forget about the pressure groups and regulators who serve to oversee the government accountability in terms of environmental friendliness and value-for-money of the project.

While each of the four types of stakeholder groups has a chance to voice their concerns, their idiosyncratic interests could obstruct any effective dialogue with their counterparts. To remove the barrier, more effort should be directed towards educating different groups of stakeholders to respect each other's concerns and suggestions (Common Ground, 2005; Deegan and Parkin, 2011). The government department should be sensitive to the grievances of the affected groups and appreciate the suggestions made by the pressure groups. Failing to accept the voice of the society would result in confrontations and criticism, which is against the governing philosophy of any responsible government (Creighton, 1999). In contrast, the groups affected by the project should respect the will of the general public and users, as many PIC facilities would help boost the economy and improve the quality of life. For the sake of the entire community, some sacrifice by a small section of the society is inevitable. Equally, the general public and users should be patient with the project-affected groups as they are the sufferers in the project. It is good practice for the pressure groups to maintain a platform of information exchange with the general public and users and the affected groups so that they can have a less biased standpoint to supervise the government and project initiator.

Acknowledging the value of mutual respect among different stakeholder groups to the success of a PIC project, it is desirable to have a common goal and value for the project as well as the public participation exercise (Deegan and Parkin, 2011; Hao et al., 2007). Hopefully, this shared goal and value is agreed by different groups of stakeholders at the outset of any public participation programme. With this in place, major stakeholders can gather together to prioritise the issues and concerns throughout the public participation process. Rietbergen-McCracken and Narayan-Parker (1998) postulated that the most critical concerns are those with the highest level of influence and of the greatest importance to the proposed project. Stakeholders should focus on the critical concerns to maximise the mutual satisfaction. Should the stakeholders fail to reach a consensus at the early stage of planning, it is worth 


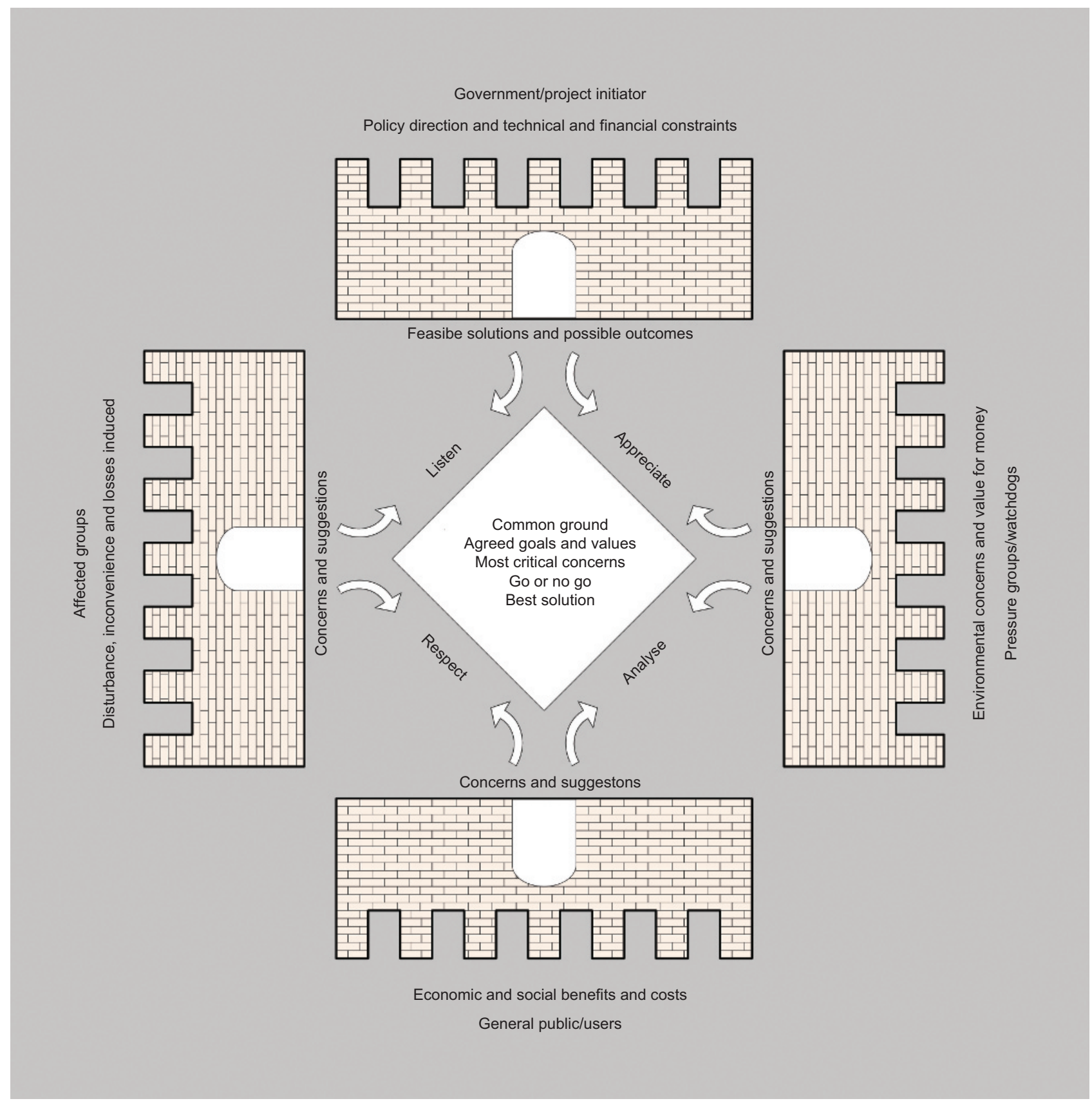

Figure 2. Consensus building among different groups of stakeholders

considering whether it is still worthwhile to go ahead with the project, as it would increase the chance of failure (El-Gohary et al., 2006; Giddings et al., 2010; Song et al., 2011). With a common ground to press ahead with the proposed project, stakeholders can then work out the best solution that could answer the diverse interests of various stakeholder groups (DETR, 2000).

\section{A systematic participatory framework}

Atkin and Skitmore (2008) and Song et al. (2011) believe that a transparent and systematic public participation process could increase the chance of project success, and this is particularly the case for highly sensitive PIC schemes, as this type of project can attract a great deal of attention from the community (CEDD, 2009; Deegan and Parkin, 2011). In Hong Kong, a 
Rethinking public participation

in infrastructure projects

$\mathrm{Ng}$, Li and Wong mega-infrastructure project which has aroused much debate recently is the Guangzhou-Shenzhen-Hong Kong express rail link project. Figure 3 shows the programme and the public participation process of this project (MTR, 2011).

The issues associated with the public participation carried out for this project include

(a) an absence of a comprehensive public participation process as the public only got a chance to be involved more extensively at the design stage

(b) a relatively short timeframe for public participation when the public had only 1 month to digest the information, which was written in a rather technical manner, and to raise their comments (Hayllar, 2010; Zhu, 2009a).

April - November 2008 January 2009 January - April 2009

January

End $2009-2015$

2015
Public participation activities

\section{District council meetings and rural committee meetings}

\section{Project programme}

One of ten major infrastructure projects in policy address

Preliminary design
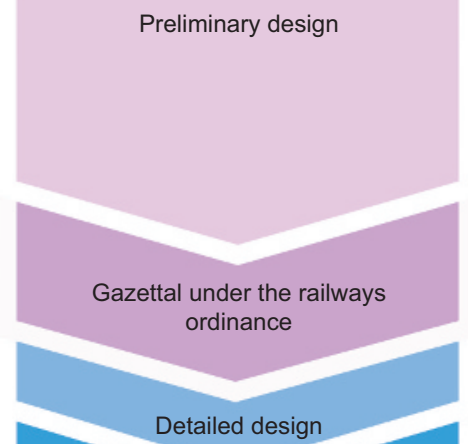

Detailed design

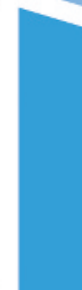

Gazettal amendments under the railways ordinance
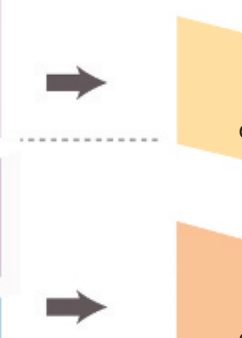

District council meetings, rural committee meetings and exhibition

September - November 2008

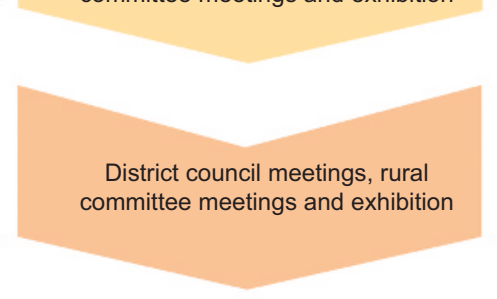

December 2008 - April 2009

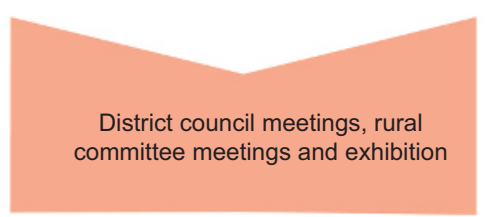

May - September 2009

Figure 3. Project programme and public participation activities for the Guangzhou-Shenzhen-Hong Kong express rail link project 
Zhu (2009a, 2009b) argued that the information dispersal techniques being adopted for most of the participatory activities in this project could be problematic, as the target should be those affected groups, especially those who may lose their homes as a result of this development. In contrast, some citizens raised criticisms that a channel for them to raise their concerns was missing (Zhu, 2009a, 2009b).

Consequently, a participatory framework for highly sensitive projects as shown in Table 1 is put forward here (CEDD,
2009). Acknowledging the possible impacts caused by this type of projects, participatory activities should be built into each project stage from inception to construction. More importantly, adequate time should be allocated to each participatory stage to ensure the necessary project information is communicated to different stakeholders and the feedback is collected from different groups (Li et al., 2012). The success of public participation for highly sensitive projects depends on a careful selection and use of participatory techniques, and those which would facilitate two-way communication such as public forum

\begin{tabular}{lrll}
\hline Project stage & Public participation activities & Scope of the involved public & Participatory techniques \\
\hline $\begin{array}{l}\text { 1. Project } \\
\text { initiation }\end{array}$ & $\begin{array}{r}1.1 \text { Involving the public in drawing up } \\
\text { the participatory strategy and in }\end{array}$ & $\begin{array}{l}\text { Government representatives; lay } \\
\text { public who are affected by, or }\end{array}$ & $\begin{array}{l}\text { Postal, online and telephone } \\
\text { surveys; exhibitions; }\end{array}$ \\
& $\begin{array}{l}\text { designing the participatory programme } \\
\text { have interest in the proposed }\end{array}$ & publication and distribution \\
1.2 Public expressing visions and desire & project; private organisations, & of consultation material; voting, \\
& for the development of concept plans & such as the design institutes & public forum; site \\
& 1.3 Establishing diversified & and construction companies; & visits and community \\
& development options with public input & professional organisations & workshops; etc.
\end{tabular}

revising and finalising outline concept plan

2. Project 2.1 Involving the public in preparing planning outline development plan and outline zoning plan

2.2 Public participation in social impact assessment and environmental impact assessment of the proposed project

2.3 Managing the expectations of the major opponents and incorporating their suggestions in revising and finalising the outline development plan and outline zoning plan

3. Project $\quad 3.1$ Incorporating public concerns in design major design revision (if there is any)

3.2 Managing the expectations of the major opponents and incorporating their concerns in revising the original design

4. Project 4.1 Consulting the public on issues construction that emerge when the proposed project is constructed

4.2 Involving the public in evaluating the whole participatory programme and educational institutions; pressure groups such as the NGOs and mass media

The relevant district councils; members of the public affected by the proposed project, representatives of the lay public who have interest in the proposed project; representatives of academia; representatives of private organisations; representatives of pressure groups and NGOs

Same as above

Same as above
Focus group meeting; face-to-face interviews; public forum; etc.

Same as above

Table 1. A systematic participatory framework for high-sensitivity PIC projects 
and face-to-face interview are favoured as they tend to attract comments from a cross-section of the community (CEDD, 2009). Decision makers should not underestimate the importance of involving the NGOs and academia as regulators and technical supporters, as their participation can improve the confidence of the public in the participatory process.

The proposed participatory framework is in line with international practice, such as that applied to the Canada Line railway projectan important regional transportation network in Canada (CLCO, 2006). To prevent the public group from being disadvantaged by the development, a thorough and comprehensive participatory programme was implemented (refer to Table 2) (Transit BC, 2006a, 2006b; Wong et al., 2009). The key features of the public participation process in the Canada Line railway project include

(a) a whole-cycle participatory process

(b) a reasonable participatory timeframe with at least 2 months being allocated to each project stage to encourage public comments and suggestions

(c) the use of diversified communication channels, for example by means of information bulletin, public notice, advertisement, survey, open house, and so on (Transit BC, 2006b).
Such a comprehensive participatory process has contributed immensely to the overall success of this project.

\section{Conclusions}

This paper has presented a systematic way to rethink the public participation process for PIC projects, and this consists of three levels of questions, namely 'who', 'what' and 'how'. The questions concerning 'who' reveal the significance of stakeholder identification and stakeholder analysis during the participation process for PIC projects. The organiser(s) should strive to find out who the decision-makers are; who the people affected by the project are; and who else should be involved in the participatory process. The constraints of the project are another aspect of critical importance to the planning and implementation of the public participation programme. Different types of constraints should be clearly identified so that clear objectives of the project and public participation exercise can be established.

Building a consensus is an essential purpose of conducting a public participation programme for both the government and the community in order to realise a harmonious society. The questions of 'how' should be addressed by the policy makers. Recognising the disparity in standpoints between various stakeholders, it is not reasonable to expect a consensus and

\begin{tabular}{cc}
\hline Duration of the \\
Project stage & participatory exercise
\end{tabular}

1. Project definition February-May 2003

2. Pre-design

October 2003-May 2004

3. Preliminary design June-August 2005

4. Detailed design January-June 2006

5. Construction

June 2006-November 2009
Participatory techniques
Consult the public on basic system elements such as proposed alignment, access, travel times, underground, at street level or elevated system, and cost Consult the public on design objectives related to station access and connections, safety and security, system design and station identity, stations in neighbourhoods and train guideway

Consult the public on specific elements of station design including station entrances, how station designs might reflect the local neighbourhood and how people get to the stations Consult the public on fewer but very specific treatments related to access, lighting, landscaping, and so on

Engage the public on the issues raised during the construction which go against social expectations
Postal, online and telephone surveys; exhibitions; information bulletins; public notices; advertisements; public forum; open house Postal, online and telephone surveys; exhibitions; information bulletins; public notices; advertisements; public forum; open house; focus group meeting; face-to-face interviews Focus group meeting; face-toface interviews; public forum; open house; and so on

Same as above

Same as above
Table 2. Public participation process for Canada Line railway project 
Rethinking public participation

in infrastructure projects

$\mathrm{Ng}$, Li and Wong hence a mutually acceptable decision be made automatically. Without understanding and prioritising the grievances of affected groups, the values to the entire society, the thoughts of the government, and the worries of the pressure groups, it is impossible to reach a consensus. In view of this, more education for the community about the value of public participation, as well as the need to respect each other, is desirable.

While the public participation activities for PIC projects are still under-explored, especially in developing countries, it is necessary to improve the transparency of the participatory process. Based on the lessons learnt from a real case of the GuangzhouShenzhen-Hong Kong express rail link project, a systematic participatory framework for PIC projects, especially those of highly sensitive nature, is proposed to guide construction practitioners and the community when public participation is conducted. The proposed framework has been compared with the public participation process of the Canada Line railway project, and it has been found that the proposed framework is in line with international practice and should be applicable to developing countries when highly sensitive projects are developed. In view of the importance of consensus building, more effort should be directed to improving the way in which consensus is reached. With the advance in various social science and information technology techniques, the consensus-building process among government and the community can be significantly improved so as to realise the governing philosophy of many governments in best serving their people.

\section{Acknowledgement}

The authors would like to thank the Research Grants Council of the Government of Hong Kong Special Administrative Region for financially supporting this study through the Public Policy Research Scheme (grant no. 7010-PPR-4).

\section{REFERENCES}

André P, Enserink B, Connor D and Croal P (2006) Public Participation International Best Practice Principles. International Association for Impact Assessment, Fargo, USA.

Arnstein SR (1969) A ladder of citizen participation. Journal of the American Institute of Planners 35(4): 216-224.

Atkin B and Skitmore M (2008) Editorial: stakeholder management in construction. Construction Management and Economics 26(6): 549-552.

Audit Commission (2002) Connecting with Users and Citizens. Belmont Press, Northampton, UK.

Batheram M, Hardin J and Whitfield S (2005) Successful participation methods for local transport planning. Proceedings of the Institution of Civil Engineers - Municipal Engineer 158(1): 9-16.

Cabinet Office (2010) A Policy Maker's Guide to Public Involvement. Cabinet Office, London, UK.

CCSG (Centre for Civil Society and Governance) (2007) From
Consultation to Civic Engagement: The Road to Better Policy-making and Governance in Hong Kong. Centre for Civil Society and Governance, The University of Hong Kong, Hong Kong.

CEDD (Civil Engineering and Development Department) (2009) Public consultation/engagement guidelines. Civil Engineering and Development Department, Hong Kong. CLCO (Canada Line Rapid Transit Incorporation) (2006) Canada Line Final Project Report. Canada Line Rapid Transit Inc., Canada.

Common Ground (2005) A Handbook for Public Participation in Environmental Assessment in Southern Africa. Institute for Environmental Assessment, South Africa.

Creighton JL (1999) How to design a public participation program. In Guiding Materials for DOE Staff and Contractors (Office of Intergovernmental and Public Accountability (ed.)). U.S. Department of Energy, Washington, DC, USA.

Creighton JL (2005) The Public Participation Handbook: Making Better Decisions through Citizen Involvement. Jossey-Bass, San Francisco, USA.

Deegan B and Parkin J (2011) Planning cycling networks: human factors and design processes. Proceedings of the Institution of Civil Engineers - Engineering Sustainability 164(1): 85-93.

DETR (Department of the Environment, Transport and the Regions) (2000) Public Participation in Making Local Environmental Decision. Department of the Environment, Transport and the Regions, London, UK.

DOE (Department of Energy) (1999) Public Participation Planning Guide. U.S. Department of Energy, Washington, DC, USA.

DOJ (Department of Justice) (2009) Guidelines for Public Participation. Department of Justice, Ottawa, Canada.

El-Gohary N, Osman H and EL-Diraby T (2006) Stakeholder management for public private partnerships. International Journal of Project Management 24(7): 595-604.

Giddings B, Porter G, Paterson E and Theobald K (2010) Participation in sustainability appraisal planning policy. Proceedings of the Institution of Civil Engineers - Municipal Engineer 163(2): 115-123.

Hampton W (1977) Research into public participation in structure planning. In Public Participation in Planning (Seawell WRD and Coppcock JT (eds)). Wiley, London, UK.

Hao JL, Hills MJ and Huang T (2007) A simulation model using system dynamic method for construction and demolition waste management in Hong Kong. Construction Innovation: Information, Process, Management 7(1): 7-21.

Hayllar MR (2010) Public-private partnerships in Hong Kong: Good governance - the essential missing ingredient? Australian Journal of Public Administration 69(S1): S99-S119. IAPP (International Association for Public Participation) (2007) 
Rethinking public participation

in infrastructure projects

$\mathrm{Ng}$, Li and Wong
IAP2 Core Values for Public Participation. International Association for Public Participation, Colorado, USA.

IFC (International Finance Corporation) (1998) Doing Better Business through Effective Public Consultation and Disclosure: A Good Practice Manual. Environment Division, International Finance Corporation, Washington, DC, USA.

Landge V, Jain SS and Parida M (2005) Community participation for road safety in India. Proceedings of the Institution of Civil Engineers - Municipal Engineer 158(1): 45-51.

Lee GKL and Chan EHW (2008) The analytic hierarchy process (AHP) approach for assessment of urban renewal proposals. Social Indicators Research 89(1): 155-168.

Li THY, Ng ST and Skitmore M (2012) Public participation in infrastructure and construction projects in China: From an EIA-based to a whole-cycle process. Habitat International. 36(1): 47-56.

Moore A and Warren A (2006) Legal advocacy in environmental public participation in China: raising the stakes and strengthening stakeholders. China Environment Series 8: 3-23.

MTR (Mass Transit Railways) (2011) Guangzhou-Shenzhen-Hong Kong Express Rail Link. The Mass Transit Railway Corporation, Hong Kong. See http://www.mtr.com.hk/eng/ projects/future_gz_sz_hk_xrl_consult.html (accessed 20/07/ 2011).

Neverauskas B and Tijūnaitienè R (2007) Public participation in city governance decision-making: Theoretical approach. Engineering Economics 54(4): 27-35.

Olander S and Landin A (2005) Evaluation of stakeholder influence in the implementation of construction projects. International Journal of Project Management 23(4): 321-328.

Olander S and Landin A (2008) A comparative study of factors affecting the external stakeholder management process. Construction Management and Economics 26(6): 553-561.

Plummer J and Taylor J (2004) Community Participation in China: Issues and Processes for Capacity Building. Earthscan/James and James, London, UK.

Rietbergen-McCracken J and Narayan-Parker D (1998) Participation and Social Assessment: Tools and Techniques. The World Bank Publications, Washington, DC, USA.

Rowe G and Frewer LJ (2000) Public participation methods: a framework for evaluation. Science, Technology and Human Values 25(1): 3-29.

Rowe G and Frewer LJ (2004) Evaluating public-participation exercises: a research agenda. Science, Technology and Human Values 29(4): 512-556.

Rowe G and Frewer LJ (2005) A typology of public engagement mechanisms. Science, Technology and Human Values 30(2): 251-290.

Sewell WRD and Phillips SD (1979) Models for evaluation of public participation programmes. Natural Resources Journal 19(2): 337-358.

Shan C and Yai T (2011) Public involvement requirements for infrastructure planning in China. Habitat International 35(1): 158-166.

Song X, Mulder K, Frostell B, Ravesteijn W and Wennersten R (2011) Transition in public participation in Chinese water management. Proceedings of the Institution of Civil Engineers - Engineering Sustainability 164(1): 71-83.

Transit BC (2006a) Public Information on the Traffic Management Strategy. British Columbia Transit Corporation, Canada.

Transit BC (2006b) Canada Line Information Bulletin. British Columbia Transit Corporation, Canada.

Wang Y (2007) A Study on the Design Issues of Guangzhou, Shenzhen and Hong Kong Express Rail Link project. Unpublished thesis for partial fulfilment of MSc, Central South University, China (in Chinese).

Woltjer J (2009) Concepts of participatory decision-making in Dutch infrastructure planning. In Public Participation and Better Environmental Decisions: The Promise and Limits of Participatory Processes for the Quality of Environmentally Related Decision-making (Coenen FHJM (ed.)). Springer, London, UK.

Wong KKW, Ng ST and Li THY (2009) Improving public engagement of PPP projects in developing economies: lessons learnt from North America. Proceedings of International Symposium on Construction in Developing Economies: Similarities among Diversities (CIB-W107). International Council for Building, Penang, Malaysia.

Zhang $X$ and Jennings E (2009) Public participation in environmental policy making in China: a case study. Proceedings of the Midwest Political Science Association 67th Annual National Conference. Midwest Political Science Association, Chicago, USA.

Zhu KD (2009a) Worse than Fake Public Consultation, see http:// www.inmediahk.net/node/1002532 (in Chinese) (accessed 24/06/2011).

Zhu KD (2009b) Administration-oriented Public Consultation, see http://www.inmediahk.net/node/1002679 (in Chinese) (accessed 24/06/2011).

\section{WHAT DO YOU THINK?}

To discuss this paper, please email up to 500 words to the editor at journals@ice.org.uk. Your contribution will be forwarded to the author(s) for a reply and, if considered appropriate by the editorial panel, will be published as discussion in a future issue of the journal.

Proceedings journals rely entirely on contributions sent in by civil engineering professionals, academics and students. Papers should be $2000-5000$ words long (briefing papers should be 1000-2000 words long), with adequate illustrations and references. You can submit your paper online via www.icevirtuallibrary.com/content/journals, where you will also find detailed author guidelines. 